\title{
Research on the Inverse Morphemes Word Pairs in Huang Kan's Interpretations of the Collected Notes on the Analects of Confucius*
}

\author{
Ling Xu \\ The College of Literature and Journalism \\ Sichuan University \\ Chengdu, China 610064 \\ School of Humanities and Public Administration \\ Jiangxi Agricultural University \\ Nanchang, China 330045
}

\author{
Zunzhang Sun \\ School of Humanities and Public Administration \\ Jiangxi Agricultural University \\ Nanchang, China 330045
}

\begin{abstract}
In Huang Kan's The Interpretations of the Collected Notes on the Analects of Confucius, the inverse morphemes word pairs can generally be grouped into two categories: one being in the strict sense $A B / B A$ both occurring at once, the other in the non-strict sense only $\mathrm{BA}$ found in Huang's the interpretations while $A B$ occurring in other synchronic or diachronic literature. In Huang's the Interpretations, $\mathbf{A B} / \mathbf{B A}$ of the inverse morphemes both are mostly coordinated and their compound structures can be classified into cognate words, synonyms and antonyms, wherein most of the synonyms are embodied only in a single form as AB in modern Chinese, which is mainly determined by intonation, historical and cultural situation and language users' psychological inclination. It implies that the word order in Chinese actually bear the effects of these three factors. Some new variations of BA pattern also occurred in Huang's the Interpretations, which represents developmental activeness of the vocabulary in the medieval times, reveals the production pathway of new words in Chinese, increases the expressiveness of vocabulary and more choices for language users, and provides some useful data for the disyllablization of Chinese vocabulary.
\end{abstract}

Keywords-Huang Kan; The Interpretations of the Collected Notes on the Analects of Confucius; the inverse morphemes word pairs

\section{INTRODUCTION}

As an important linguistic phenomenon in the development of Chinese vocabulary, inverse morphemes word pairs have attracted the attention of scholars as early as the Qing Dynasty. Wang Qi of Qing Dynasty wrote Annotations to Li Changji's Poems, and it says "in late

*Fund projects: Jiangxi Social Science Planning Project "Comparative Study of Four Annotations to the Analects of Confucius from Six Dynasties to Song Dynasty" (17YY07); Humanities and Social Science Project of Jiangxi Universities "Research on Annotations to the Analects of Confucius from Han and Wei to Six Dynasties" (YY1524); Major Project of National Social Science Fund "General History of Chinese Vocabulary" (14ZDB093).

CLC No: H131 Document identification code: A autumn, the bright and clear sky combines with water." In this verse, “帖妥” is the upside down writing of “妥帖”. It means that neat and tidy posts are unstable. Han Tuizhi's Poems of Yuanhe Shengde wrote "the round altar is very appropriate". Is it a commonly used inverted sentence at that time? [1] (p.293) Mr. Ding Mianzai believes that "the origin of words with same morpheme is as old as the general origin of compound words" [2]. It can be seen that it is necessary to discuss the inverse morphemes word pairs in the literature of different periods. It can provide abundant materials for discussing the formation and development of compound words and determining the generation age of compound words. There have been many achievements on inverse morphemes word pairs.

In the Liang State of the Southern Dynasties, Huang Kan wrote The Interpretations of the Collected Notes on the Analects of Confucius (hereinafter referred to as the Interpretations) which is a representative work of the existing annotations of Confucius classics. It is a great achievement of the annotations of the Metaphysics Analects of Confucius in the Six Dynasties and occupies a unique position in the history of the study of The Analects of Confucius. The study of inverse morphemes word pairs in the polysyllabic words cannot only summarize the structural characteristics of its own polysyllabic words, but also provide important corpus for the polysyllabic words in Middle Chinese.

In the Interpretations, the inverse morphemes word pairs can be divided into two categories according to the form. One is in the strict sense. Namely, there are 37 groups of 74 words in both $\mathrm{AB}$ and $\mathrm{BA}$ forms. The other is in non-strict sense. Namely, there is BA form in the Interpretations. There are a total of 35 words of $\mathrm{AB}$ form in the synchronic or diachronic literature.

According to word class, lists 37 groups of inverse morphemes word pairs with $\mathrm{AB} / \mathrm{BA}$ in the Interpretations as follows: 
TABLE I. THE INVERSE MORPHEMES WORD PAIRS

\begin{tabular}{|l|l|l|l|l|l|l|}
\hline $\begin{array}{l}\text { Word } \\
\text { Class }\end{array}$ & Verb & Noun & $\begin{array}{c}\text { Adjec } \\
\text { tive }\end{array}$ & $\begin{array}{c}\text { Adver } \\
\text { b }\end{array}$ & Special $^{\mathbf{1}}$ & Total \\
\hline Qty & 23 & 10 & 1 & 2 & 1 & 38 \\
\hline Rate & $62.2 \%$ & $19.2 \%$ & $2.4 \%$ & $4.9 \%$ & $2.6 \%$ & $\begin{array}{l}100.0 \\
\%\end{array}$ \\
\hline
\end{tabular}

As shown in the "Table I", the inverse morphemes word pairs in the Interpretations are predominantly substantive words such as verbs and nouns, while there are fewer word classes of adjectives and adverbs tending to describe more abstract meanings. This is basically consistent with the trend of the distribution of word class of inverse morphemes word pairs in other literatures. For example, in Che Shuya's survey of Han Feizi, there are 69 groups of inverse morphemes word pairs. There are three classes of word, noun, verb and adjective. The number of nouns is the most, and there are total 27 groups [3]. Hong Shuai made a survey on Mencius. There are 69 inverse morphemes word pairs. There are four classes, verb, noun, adjective and adverb. The numbers of nouns and verbs are the most, and there are total 58. There are only 5 adverbs [4]. In the survey of Huang Jianning on Taiping Classics, there are 160 inverse morphemes word pairs and four classes, including verb, noun, adjective and adverb. The number of verbs is the most and there are 74 . There are only 2 adverbs [5]. Among the 196 groups of inverse morpheme word pairs in Dunhuang Bianwen collected by Chen Mingye, there are five categories: verb, noun, adjective, adverb and conjunction. The numbers of verb and noun are the most, respectively accounting for $43.88 \%$ and $35.20 \%$. But there are four groups of conjunctions [6]. This shows that the formation of inverse morphemes word pairs in the Interpretations not only conforms to the dominated development law of Chinese polyphonic whole notional words, but also conforms to the stage characteristics of inverse morphemes word pairs themselves. That is to say, in the Middle age and before, the inverse morphemes word pairs mainly are nouns and verbs. After that period, other word classes were also influenced by them.

Next, we will analyze the inverse morphemes word pairs in forms of $\mathrm{AB}$ and $\mathrm{BA}$ in the Interpretations from the aspects of grammar, semantics, morpheme composition and diachronic development.

\section{SEMANTIC AND GRAMMATICAL STRUCTURE}

\section{A. Coordinative Word Pairs of Same Grammatical Structure But Changed Meanings and Classes in $A B$ and BA Form}

This kind of word pairs accounts for the majority in the Interpretations. There are a total of 26 groups. There are 18 groups of verbs, including “断决/决断”, “绝尘/尘绝”, “兼并/并 兼”, “爱憎/憎爱”, “反返/返反”, “尽竭/竭尽”, “进前/前进”, “毁谤/ 谤毁”, “盟会/会盟”, “还退/退还”, “说解/解说”, “敛聚/聚敛”, “恶 憎/憎恶”, “废兴/兴废”, “匹配/配匹”, “费损/损费”, “启发/发启”

This kind of words refers to the different word-formation order of different word class. For example, "约俭" is a verb, while "俭约" is an adjective. and “授受/受授”. There are five groups of nouns, including “大小/小大”, “过失/失过”, “终始/始终”, “友朋/朋友” and “位爵/ 爵位”. There is one group of adjective and two groups of adverbs, respectively “诡诈/诈诡”, “互相/相互” and “几庶/庶 几”.

\section{[cost/ lose] (“费损/损费”)}

Both of them mean cost and lose.

Confucius said, "the way to be an official is to benefit the people and lose you nothing". That is to say, "gives others favors and cost you nothing" [7] (P 302 below).

When a wise emperor carries out his policies, he handled them according to his own circumstances. He wouldn't let people adapted to living in water live on mountains or in the Central Plains. It is based on the characteristics of the people to implement favorable policies for them. In this way, the wise emperor will lose nothing. [7] (P 302 below)

\section{[Each other/ one anther] (“互相/相互”)}

Both of them mean each other.

Is it not the sincere words of wise men that work for each other? [7] (P 239 below)

Now the reason for the saying that "there will be no poverty if wealth is distributed equally, and no loneliness if people live in harmony", and that "with peace and tranquility, it will not collapse" is because of considering each other's interests. Equal distribution and harmonious coexistence lead to peace and non-collapse. [7] (P 277 below)

\section{B. Coordinative Word Pairs of Same Grammatical Structure and Class But of Different Meanings in AB and BA Form}

There are 9 groups of such word pairs. Among them, there are 3 groups of verbs, including “执持/持执”, “伤痛/痛 伤” and “谋图/图谋”. There are 6 groups of nouns, including “性情/情性”, “甲兵/兵甲”, “容仪/仪容”, “子弟/弟子”, “民人/人民” and “力势/势力”. The meanings of word pairs in AB and BA from are not developed synchronously, which is the main reason for the generation of different meanings of inverse morphemes word pairs.

\section{[People/ population] (“民人/人民”)}

Relied on these people to manage the country, and the monarch owned people and land for nothing. [7] (P 240 below)

Here "people" refers to common people, focusing on "people".

After the Zhou Dynasty inherited the Shang Dynasty, the population was greatly reduced, so each person was given $100 \mathrm{mu}$ of land. [7] (P 245 below)

Here "people" refers to the population in a broad sense, focusing on "number of people".

[Scheme/ plan] (“图谋/谋图”) 
When planning things for others, we should be loyal and with all our heart. How can we only be loyal but without our heart? [7] (P 160 below)

Here "图谋" refers to "planning”, and focuses on "plan". Shuowen · Yanbu: "planning means to solve difficulties." [8] (P 52 above)

It warns people that they should concentrate on their own duties and don't covet others' regimes. [7] (P 264 above)

Here "谋图" refers to making profits and conspiracy, which contains derogatory meanings. Under this meaning, the Great Dictionary exemplifies The General Message of Awakening the World. Too late, this article can advance the documentary evidence of the Great Dictionary.

\section{[Strength / power] (“力势/势力”)}

If other people should have power, then my strength and power can not diminish others. For people like Bo Liao, my strength and power can make Ji Sun judge $\mathrm{Zi}$ Lu innocent and kill Bo Liao in front of the public. [7] (P 265 below)

Here "力势" refers to strength and power. The meaning is specific.

Ran You said, "Zhuanyu has firm cities, strong armies and sharp weapons, and it is close to Feicheng. Our national strength is powerful now, so it is possible for us to wipe out Zhuanyu. If we don't merged it, then this country will invade our Feicheng one day, which will be the scourge of our future generations". [7] (P 276 below)

Here "势力" refers to political, economic, military and other powers, the meaning of which is abstract.

\section{Inverse Morphemes Word Pairs of Different Grammatical Structures and the Meaning But Same Class}

There are 2 groups. Verbs: “辨明/明辨”; one group of noun: “田农/农田”2

\section{[Farming/farmland] (“田农/农田”)}

Shuowen · “舅” Radical wrote: “ “舅” means cultivation” [8] (P 60 above). “留” is the complex character of “农”. Shuowen - Farmland wrote: "farmland means cropland. It is the land for plants and trees. Use small paths to divide boundaries" [8] (P 290 below).

“农田” is of attributive structure, which means land for cultivation. For instance,

So, the article Imperial Governance wrote: "according to the system, there are one hundred mu of land for each person which can raise at least 9 people". [7] (P 161 below)

“田农” is of subject-predicate structure, which means farming. For instance,

\footnotetext{
$2 \quad H e r e$ "农田" and above "性情" above are all from the sentences quoted by Huang Kan in the pre-Qin literature. We also regard them as the same group of $\mathrm{AB} / \mathrm{BA}$ in the Interpretations.
}

As for the method of farming, it will be beneficial to agricultural production, that is, to do our best for our country. [7] (P 218 above)

\section{Inverse Morphemes Word Pairs of Same Grammatical Structure But of Different Classes and Meanings}

A total of 1 group: “约俭/俭约”. “约俭” is a verb, while “俭 约" is an adjective.

\section{[Restrain/ thrifty] (约俭/俭约)}

Shuowen · “人” Radical says, "thrifty is economic" [8] (P 165 below). Shuowen . “" " Radical says: "restriction is entanglement and restraint" [8] (P 272 below).

If one can restrain his words and deeds, he can return to etiquette. This is the manifestation of benevolence and righteousness. [7] (P 243 above)

Here "约俭 " means "restrict" and "restrain" one's behavior, and its meaning tends to "约”.

Silk fabrics are easy to weave, so what is easy to weave is economic, so that's the way to say "economic"[7] (P 252 below).

Here "俭约" means thrifty and economic, and the compound meaning tends to "俭".

\section{MORPHEME STRUCTURE}

Mr. Fang Yixin pointed out when discussing the corpus of Eastern Han Dynasty: "Among the newly added polysyllabic words, the juxtaposed polysyllabic words consisting of near synonyms and synonyms account for a considerable proportion. At the beginning of their emergence, these words were often of same morphemes and inverse orders. Although this situation has been seen in the Pre-Qin Dynasty, it was very common in the Han Dynasty, especially in the Eastern Han Dynasty" [10]. This conclusion is also applicable in the analysis of inverse morpheme word pairs in $\mathrm{AB} / \mathrm{BA}$ form in the Interpretations. 35 groups of coordinative inverse morpheme word pairs in the Interpretations are mainly composed synonym morphemes, near synonym morphemes and analogous morphemes.

\section{A. Homologous Morpheme Combination}

Mr. Liu Youxin believes that "the homologous words formed by the bi-directional or reverse extension differentiation of word meanings are relatively easy to combine" [11]. There are three groups of such combinations in the Interpretations: “反返/返反”, “受授/授受” and “配匹/匹 配”. And the meanings and class of $\mathrm{AB}$ and $\mathrm{BA}$ form are unchanged.

\section{[Grant / receive] $($ 授受/受授 $)$}

They have the meaning of confer and import. Shuowen . " $\square$ " Radical says: " "give' has the meaning of "impart" [8] (P 84 below) Shuowen . "手” Radical says, " "impart' means 'give"' [8] (P 253 below). They both belong to the same initial. Wang Li's Cognate Dictionary holds that 
"受" and "授" are homologous. [12] (P 238) This pair of words was also used in the Interpretations, for example,

Every time pass something on to each other, even if you're sitting in a seat, turn your back half and bow your hand to someone else when they're giving you a message. [7] (P 227 below)

It is appropriate to receive right and grant right, so Confucius lamented that Shun could govern the country without doing anything. [7] (P 69 below)

\section{[Match / go with] (“匹配/配匹”)}

The initial consonants of "匹" and “配” are all "p" and are of same pronunciation. The Book of Songs - Daya - Wenwang Yousheng: "dig city ditches and build city walls, well matching with the city". Mao Heng said, " 'match' means 'go with" [13] (P 536 Mid.). Both of them share the same central semantics of "matching ". Wang Li's Cognate Dictionary holds that “腺”, “妃”, “匹” and “配” are of same origin [12] (P 426) . For example,

The reason why we say “匹夫” is because this person's status is relatively low and only match with couple. [7] (P 225 above)

He said that his morality is not high, only go with his wife. [7] (P 262 below)

To sum up, among the phonological and semantic related homologous morphemes, all the sememes or central sememes of the source word and the corresponding word are the same. Compounds consist mostly of associative forms, and there is no difference in word class and meaning.

\section{B. Synonymous or Semantic Morpheme Combination}

There are 28 groups of these words, which account for the majority of the inverse morphemes word pairs in the Interpretations. The meanings of these words are biased according to whether the focus of semantic expression in the context is equal or not. When the focus of semantic expression in context is average, there is no change in meaning or word class between same morpheme words with different orders.

\section{[Position/ title] (“位爵/爵位”)}

All refer to the title of nobility. For example,

If we say the title of an official is very noble, we say he cannot walk but taking a cart. [7] (P 235 below)

At that time, Confucius was afraid that there was no redundant title, so Confucius was not appreciated. [7] (P 184 below)

However, in context, the focus of semantic expression is on the former morpheme or the latter morpheme, which makes the meaning of a word deviate and refers to one side.

\section{[Looks/ appearance] “容仪/仪容”}

Shuowen . “宑” Radical said: “ “容” refers to one's 'looks' [8] (P 150 below)”. It lays emphasis on one's bearing. Shuowen . “人” Radical says: “ “仪' refers to a person's appearance and grace" [8] (P 165 below). “容” and “仪” are two categories related to people's words and manners, for example,

Secondly, let oneself behave mildly, which is called having bearing. [7] (P 178 above)

“容仪” refers to looks, which tends to “容”.

Appearance and expression are called proper appearance and manners. [7] (P 213 below)

"仪容" means appearance, which tends to "仪".

\section{Antonymic Morpheme Combination}

There are four groups in this category, including “大小/小 大”, “爱憎/憎爱”, “兴废/废兴” and “始终/终始”. The characteristics of this kind of compound words are that the solidification between morphemes is not very close, and the transition marks from phrases to words are obvious. In this kind of compound words, the use frequency of positive morpheme meaning in the former in $\mathrm{AB}$ form is higher than that of negative morpheme in the former in BA form, and it is easier to retain it in modern Chinese. It can be seen that cultural psychology plays a selective role in word order.

[From beginning to end / all along] (“始终/终始”)

It refers to the whole process from the beginning to the end. For example,

Even if people of low status come to me modestly to ask questions, I tell him without concealment and make no difference. This is the way to treat things sincerity from beginning to end. [7] (P 221 above)

Only a person of high morality can be consistent and not treated differently in order of arrival. [7] (P 297 above)

In modern Chinese, "终始" is eliminated, while "始终" is retained, and the use of adverbs has been developed, which has the meanings of "always" and "eventually".

\section{CHANGES IN THE DiACHRONIC DEVELOPMENT}

Vocabulary is one of the most sensitive elements in the development of language. The changes of daily production, life, society and things will be reflected in language practice, and the vocabulary system will change from old to new. The inverse morphemes word pairs in the Interpretations also reflect the change of vocabulary metabolism in the Middle Ages in one aspect.

\section{A. Diachronic Development of Inverse Morphemes Word}

\section{Pairs in the Interpretations}

Firstly, among inverse morphemes word pairs of AB/BA forms in the Interpretations, only 27 in $\mathrm{AB}$ form are retained in modern Chinese. They are “兼并”, “决断”, “竭尽”, “授受”, “毁 谤”, “退还”, “解说”, “伤痛”, “聚敛”, “图谋”, “憎恶”, “匹配”, “启发”, “性 情”, “过失”, “势力”, “始终”, “朋友”, “甲兵”, “人民”, “仪容”, “嚼位”, “农 田”, “大小”, “涺诈”, “庶几” and “俭约”. Among them, the 9 words of “兼并”, “退还”, “伤痛”, “匹配”, “过失”, “势力”, “始终”, “甲兵” and “人民” have different meanings from modern Chinese. 


\section{[Merge] (“兼并”)}

Those who can make rites and music for the country must have both ability and virtue. Such people can become leaders. [7] (P 164 above)

"Shuowen . “从” Radical says: " “并' means put two people together" [8] (P 169 above). Here “兼并” has the meaning of "possess" and "satisfy both sides". It is the combination of original meanings of “兼” and “并”. But in modern Chinese, “兼并” means “merge”. It refers to merging land or embezzling economy. This meaning has already come into being before the Qin Dynasty. For example,

Now the kings of the country oppress and merge each other. [14] (P 218)

It can be seen that the Interpretations has used the combination of original meanings of “兼” and “并”.

[Return] (“退还”)

When return back to his room... [7] (P 168 above)

"退", in Shuowen . “玍” Radical, "refers to "return”" [8] (P 43 below). It says ““还” means 'reply' [8] (P 40 below)”. In the Interpretations, “退还” means “return”. In modern Chinese, “退还” has the meanings of "give back", and this meaning originated in modern times. For instance,

If he says so, you needn't return it. (Chapter 42, Strange Situations in Past 20 Years, Wu Jianren, Qing Dynasty) [15] (P 380)

To sum up, the inverse morphemes word pairs in the Interpretations has suffered elimination and selection in the diachronic development, and only the inverse morphemes word in $\mathrm{AB}$ form are left. It is the result of the economic principle of language. As Mr. Wang Li said, "in spoken language, it is not sustainable for synonyms to achieve full equivalence in meaning" [16] (P 497). When the semantics and expressive functions of inverse morphemes word pairs are identical, one of them becomes redundant and is gradually eliminated. This choice also promotes the continuous change and development of the meaning of a word. The phenomenon of polysemy is the presentation of the diachronic development of vocabulary.

Secondly, the inverse morphemes word pairs of both $A B$ and BA form in the Interpretations having been preserved in modern Chinese are “竬明/明辩”, “子弟/弟子”, “互相/相互”, “进 前/前进”, “爱憎/憎爱” and “废兴/ 兴废”. Among them, the meanings and usages of “爱憎/憎爱”, “废兴/兴废” and “互相/相 互” have not changed in modern Chinese. For example, "互相 /相互" refer to “each other”. The meanings and usages of “辩 明/明辩” and “子弟/弟子” in the Interpretations are different from modern Chinese. It continues this distinctive meaning in modern Chinese, such as:

\section{[Son /disciple] (“弟子/子弟”)}

To be a son and brother, we should be filial and friendly. [7] (P 162 above)

The article Xian Jin is about the order of priority in apprenticing a master. [7] (P 234 above)
The term "弟子" originally refers to disciple, and generally refers to junior. In the interpretations, it refers to disciple. “子弟” originally refers to children and brother. For father and elder brothers, it refers to children and nephews, and also refers to younger generation.

Both of them show that the combinations and meanings of these two compound words are relatively fixed and become a relatively stable category in the development of vocabulary, so they are not easy to be eliminated.

The meanings and usages of “前进/进前” are not different in the Interpretations. But in modern Chinese there are differences in meaning and usage. “前进” means "go ahead", while “进前” means “walk forward”. “前进” is often used in written language and "进前" is used in spoken language. Such words in the Interpretations reflect that they are in the transitional period of the formation of compound words and are the critical point of phrase-to-word conversion.

Thirdly, compared with modern Chinese, the inverse morphemes word pairs of both $\mathrm{AB}$ and $\mathrm{BA}$ form in the Interpretations have been eliminated. They are “反返/返反”, “执持/持执”, “盟会/会盟” and “费损/损费”. This kind of words are seldom used in modern times and not retained in modern Chinese. It mainly lies in two aspects. First, word changed along with the change of semantics, which is the result of vocabulary replacement. For example, "返反" is replaced by the synonym "返回"; “费损/损费” are replaced by “损耗”. In addition, it is also the reflection of historical and cultural context and social changes in vocabulary. For instance, “盟会 /会盟” and “执持/持执” with classical flavor have been eliminated by society.

\section{B. The Diachronic Development of BA-form Non-strict Inverse Morphemes Word Pairs in the Interpretations}

There are $35 \mathrm{BA}$-form non-strict inverse morpheme word pairs in the Interpretations, which are mainly reflected in the following aspects compared with modern Chinese.

Firstly, before the Interpretations, $\mathrm{AB} / \mathrm{BA}$ forms have been used in other literatures. There are some inverse morpheme words that the Interpretations only reserved BA form while modern Chinese retained its $\mathrm{AB}$ form. And their word classes and meaning are not changed. They are 6 groups of verbs, including “答对”, “变改”, “去失”, “合结”, “犯 触” and “抚安”, and four groups of nouns, including “埃尘”, “绳准”, “阻险” and “物器”.

\section{[Lose] (“去失”)}

In learning, if there is a harvest, keep it carefully. It looks like someone with a treasure in hand is afraid of losing, so he is very careful. [7] (P 216)

Here "去失" means "disappear" or "lose", and it is a verb. “失去” with this meaning has appeared in the Eastern Han Dynasty. For example,

If a prince loses his country, he can temporarily entrust himself to other principalities, which is the ancient etiquette. (Chapters and Sentences of Mencius · Wanzhang II, Zhao Qi of the Eastern Han Dynasty) [13] (P 2745 Mid.) 
The use case under the meaning in "Great Dictionary" is in Tang Fanggan's poem Waterfall in Mount Dongshan, which can be advanced.

Secondly, before the Interpretations, some inverse morpheme word pairs of $\mathrm{AB} / \mathrm{BA}$ form had been found in other literature but only $\mathrm{AB}$ form are retained in modern Chinese. Their meanings and word classes changed. Among such word pairs, there are four groups of verbs, including “制 节”, “驰驱”, “坏败” and “承奉”, and 3 groups of nouns, including “记传”, “言语” and “室家”, and 2 groups of adjective, including “均平” and “和柔”.

\section{[Corrupt] (“坏败”)}

Li Chong said, "These are the names of corrupt food" [7] (P 230 below).

Here "坏败" refers corrupt food, and it is a adjective. This meaning is not included in the Great Dictionary. As a verb, “败坏” means “damage", which has been used in Historical Records, for instance,

Damage his credit. (Biography of Cool Officials · Historical Records) [17] (P 3793)

\section{[Abstain] (“制节”)}

A sick person should abstain from eating. [7] (P 205 below)

Here, “制节” refers to "restrain” and "limit”, and is a verb. “节制” is not found to be used in the Interpretations. But in other literatures, it is very common. It is used in both verb and noun, for instance,

The powerful army of Qin State cannot resist the legal system of Jin State. (Xunzi · Yibing) [19] (P 274)

Here "节制" is a noun, meaning moral standards and legal system.

As a verb, it has the meaning of "control" and "restraint", for example,

Control diet, and don't waste. (Annals of Three Kingdoms · Shu Zhi · Biography of Jiang Wei, Chen Shou) [20] (P 1068)

As a verb, it also has the meaning of "command" and "administrate", for instance,

If a general can establish his dignity, the soldier can be easily managed and commanded, and the command issued by the general can be clearly executed. (Wei Liaozi · Military Order II) [21] (Vol. 736, P 88 below)

This meaning has been retained in modern Chinese.

$$
\text { [Just] (“均平”) }
$$

If politics is just, then the country will be rich and strong. [7] (P 277 above)

"均平" here means "just and sound", and is an adjective. In modern Chinese, we have “平均” and means "even", with no difference in weight or number, or equal distribution in mathematics. It is different from "均平".
Thirdly, some inverse morpheme word pairs in $\mathrm{AB}$ form came into being before the Interpretations, and generated new words in BA form in the Interpretations. Modern Chinese only reserved the $\mathrm{AB}$ form, and word classes and meanings of them are not changed. There are one group of verb, “过超”, and two groups of nouns, “谋智” and “富财”.

\section{[Intelligence] (“谋智”)}

Even if talent and strategy can be competent, if one cannot maintain his official position without benevolence and righteousness" [7] (P 274).

"谋智" means “wisdom and strategy”. It had been born before the Interpretations, for example,

A man of moral benevolence can win, and a man of wisdom can win. (Guan Zi · Bayan) [22] (P 472)

The earliest use case of "Great Dictionary" is in Yuan Gao Wenxiu's Xiangyang Hui, late, and can be advanced.

The substitution of BA form in the Interpretations by $\mathrm{AB}$ form in modern Chinese is largely due to the influence of Chinese tone on word order. Most of these words are adjusted and selected according to the order of four tones. For example, “去失” has the meaning of "lose", and is a verb. Now it also has the meaning of lose, and with same usage and obvious tone order. As for strict inverse morpheme word pairs in the Interpretations, we only serve $A B$ form in modern Chinese, and there are also factors of tone selection. Modern Chinese also reserve some words of $\mathrm{AB}$ form which are contrary to the tone order, such as, “承奉”, “埃尘”, “记传”, “谋智”, “物器” “材木” and “绳准”. It should be caused by the unbalanced development of pragmatic habits and morpheme meanings. The development of morpheme meanings in compound words is not synchronous. The BA form of literal combination meanings is replaced by the $\mathrm{AB}$ form which uses high frequency and relatively abstract semantics. For example,

\section{[Flatter] (“承奉”)}

The so-called filial piety is not to violate the orders of parents. [7] (P 167 below)

“承奉” had the meaning of "receive instructions and observe". Before the Interpretations, there are both “承奉” and “奉承” in other literatures. For example,

Flatter relatives and promote wives and children. (Mo $\mathrm{Zi} \cdot$ Universal Love II)[14] (P 118)

In modern Chinese, “奉承” means “flatter". It uses the extended meaning, which has come into being in modern Chinese. For instance,

Children are still young, if flatter them excessively, it will develop their luxury character. (History of Jin State · Shizong Jizhong) [23] (P 173)

Fourthly, the new words of BA-form produced in the Interpretations and $\mathrm{AB}$ form after the Interpretations are all retained in modern Chinese. The meanings of the words have not changed, but the usage situation has changed. There are 
two groups of verbs, “加添” and “荐举”, and one group of noun, “由来”.

$$
\text { [Add] (“加添”) }
$$
below)

Add and increase literary allied languages. [7] (P 258

"Add" here means “increase”. The earliest use case of “加 添” in the Great Dictionary was in the Tang Dynasty. The earliest use case of "添加" in the Great Dictionary was also the Tang Dynasty.

Fifthly, there were two forms of $\mathrm{AB} / \mathrm{BA}$ in the literature before the Interpretations. In the Interpretations, there is only $\mathrm{BA}$ form, while both $\mathrm{AB}$ and $\mathrm{BA}$ form are retained in modern Chinese. The meaning or usage occasion of words are changed. There are three groups of verbs in this category: “导引”, “骂辱” and “言语”; two groups of nouns in this category: “音声” and “材木”.

\section{[Insult] (“骂辱”)}

If people warn others for many times and they still don't listen, they will be insulted. [7] (P 249 above)

Here it means abuse and insult. “骂辱” and “辱骂” have been used in the literature before the Interpretations. For example,

Sun Quan was very angry when Guan Yu insulted the envoy who proposed marriage and refused to marry him. (Records of the Three Kingdoms, Shu Zhi, Guanyu Biography) [19] (P 941)

In modern Chinese, "辱骂" is used in written language, and "骂辱" is often used in spoken language or dialect.

\section{CONCLUSION}

The formation characteristics of inverse morphemes word pairs in the Interpretations indicate that the inversion of word order was still an important way to generate compound words at that time. At the same time, from the diachronic development of these word pairs in the Interpretations, the existence of Chinese vocabulary is the result of gradual selection and elimination. In the formation course of Chinese disyllabic words, the coordinated word-building is the main structural form of Chinese vocabulary formation. The inverse morphemes word pairs in the Interpretations also fully reflect this trend that build words by coordinating main homologous morphemes, synonymous morphemes and antonymous morphemes of the two sides, and the semantic relationship between each group of morphemes is relatively close.

As of most inverse morphemes word pairs in $\mathrm{AB}$ and $\mathrm{BA}$ form in the Interpretations with same meaning, modern Chinese only reserved $\mathrm{AB}$ form. This single-form sequence selection is mainly caused by Chinese tone, the historical and cultural context of the language, and the user's inclination psychology. This shows that the choice of Chinese vocabulary order is influenced by the above factors. At the same time, it also shows that many compound words in the Middle Ages were still in the transitional period, which was the stage from phrase to solidification of words. Many compound words, as Mr. Liu Shuxin thinks, are words with critical points. [24] (P 57-58) In the Interpretations, both AB and $\mathrm{BA}$ are not retained much in modern Chinese, but most of these words are mature words with abstract meanings, extensive use and high stability.

There are also some new BA-type words in the Interpretations. The appearance of these words has reflected the activity of vocabulary development in the Middle Ages, showed the way to produce Chinese new words, increased the expressive power of vocabulary and the flexible space for people to choose and use vocabulary, and provided some useful corpus for the development of Chinese vocabulary polyphony.

\section{ACKNOWLEDGMENT}

I thank Professor Fang Yixin of Zhejiang University for his guidance in the writing of this article.

\section{REFERENCES}

[1] Li He, Wang Qi. Annotations to Li He's Poems. Shanghai: Shanghai People's Publishing House, 1977. (in Chinese)

[2] Ding Mianzai. The Relationship between the Structure and Meaning of Words with Same Morphemes. Academic Monthly. 1957, (2): 4854. (in Chinese)

[3] Che Shuya. A Study of Disyllabic Words with Same Morphemes and Different Order in Han Feizi. Language Studies. 2005, (1): 113-118. (in Chinese)

[4] Hong Shuai. Inverse Morpheme Word Pairs in Zhao's Notes to Mencius. Journal of Chongqing Institute of Technology: Social Sciences Edition. 2009, (10): 126-130. (in Chinese)

[5] Huang Jianning. Inverse Morpheme Word Pairs in Taiping Classics. Journal of Sichuan Normal University: Social Science Edition. 2001, (1): 62-66. (in Chinese)

[6] Chen Ming'e. Characteristics and Causes of Inverse Morpheme Word Pairs in Dunhuang Bianwen. Journal of Zhongnan University: Social Sciences Edition. 2004, (10): 654-658. (in Chinese)

[7] Huang Kan. The Interpretations of the Collected Notes on Analects of Confucius. Analects of Confucius (Four Series of Annotations to Key Books). Beijing: China Book Company, 1998. (in Chinese)

[8] Xu Shen. Shuowen Jiezi. Beijing: Zhonghua Publishing House, 1963. (in Chinese)

[9] Xu Shen, Duan Yucai. Commentary on Shuowen Jiezi (2nd edition) [M]. Shanghai: Shanghai Ancient Books Publishing House, 1988. (in Chinese)

[10] Fang Yixin. A Brief Discussion on the Study of Corpus and Lexical History of Eastern Han Dynasty. Chinese Language. 1996, (2): 140144. (in Chinese)

[11] Liu Youxin. Word-formation Rules of Chinese Homologous Compound Words. Academic Records. Chengdu: Bashu Book Soceity, 2002. (in Chinese)

[12] Wang Li. Cognate Dictionary. Beijing: Commercial Press, 1982. (in Chinese)

[13] Ruan Yuan. Notes on the Thirteen Classics. Beijing: Zhonghua Book Company, 1980. (in Chinese)

[14] Sun Yirang, Sun Qizhi, Mozi Jiangu. Beijing: Zhonghua Book Company, 2001. (in Chinese)

[15] Wu Jianren. Strange Situations in Past 20 Years. Beijing: People's Literature Publishing House, 2000. (in Chinese)

[16] Wang Li. Historical Manuscript of Chinese. Beijing: Zhonghua Book Company, 1980. (in Chinese) 
[17] Sima Qian. Historical Records. Beijing: Zhonghua Book Company, 2013. (in Chinese)

[18] Wang Xianqian, Shen Xiaohuan, et al. Xunzi Jijie (II). Beijing: Zhonghua Book Company, 1988. (in Chinese)

[19] Chen Shou. Records of the Three Kingdoms. Beijing: Zhonghua Book Company, 1964. (in Chinese)

[20] Siku Quanshu. Shanghai: Shanghai Ancient Books Publishing House, 1987. (in Chinese)

[21] Li Xiangfeng, Liang Yunhua. Guanzi Jiaozhu. Beijing: Zhonghua Book Company, 2004. (in Chinese)

[22] Fan Ye. Hou Han Shu. Beijing: Zhonghua Book Company, 1965. (in Chinese)

[23] Tuo Tuo, et al. History of Jin State. Beijing: Zhonghua Book Company, 1975. (in Chinese)

[24] Liu Shuxin. Vocabulary Research. Beijing: Foreign Language Teaching and Research Press, 2006. (in Chinese). 